\title{
Screening older people with musculoskeletal pain for depressive symptoms in primary care
}

\author{
Christian David Mallen and George Peat
}

\begin{abstract}
Background

Older patients presenting to GPs with musculoskeletal pain are at high risk of having concurrent depression.

Aim

To investigate the performance of ultra-short (1-4 items tools) screening questions used during the consultation, and through a patient questionnaire to detect depressive symptoms among older adults presenting with musculoskeletal pain to general practice.

Design of study

Cross-sectional survey, linked GP consultation data.

Setting

General practices in central Cheshire, UK.

Method

Consecutive patients aged $\geq 50$ years presenting with non-inflammatory musculoskeletal pain were eligible to participate. GPs screened all patients in the consultation for the presence of depressive symptoms using two questions. All patients were sent a postal questionnaire within 1 week of consultation containing the Hospital Anxiety and Depression Scale and the written version of the depression screening questions.

Results

The total number of patients included in the study was 428. In total, $35.5 \%$ of consulters had comorbid depressive symptoms, with $13.5 \%$ experiencing moderate or severe symptoms. Just over half of participants $(n=218 / 242 ; 51.4 \%)$ screened positive on self-administered screening at home compared with only $78(20.8 \%)$ on GP-administered screening in the consultation. There was little difference between GPadministered and self-administered screening in the probability of depressive symptoms among those who screened positive with regard to exhibiting signs of having depressive symptoms.

Conclusion

Older patients consulting their GP with musculoskeletal pain frequently have comorbid mental ill health. Ultrashort depression screening questions administered during the consultation miss a large number of those with depressive symptoms, including six out of eight patients with severe symptoms. An improvement in the performance of screening questions in this patient group or narrowing the definition of 'high risk' from all patients aged $\geq 50$ years presenting with musculoskeletal pain could help to improve detection.

\section{Keywords}

depression; general practice; musculoskeletal pain; screening.
\end{abstract}

\section{INTRODUCTION}

Depression is a common condition that is frequently encountered in UK general practice, where it affects between $5 \%$ and $15 \%$ of all individuals. ${ }^{1-3}$ Although depression represents the third most common reason for consultation, the diagnosis is frequently missed in primary care settings, ${ }^{4-7}$ largely because patients often present with somatic symptoms ${ }^{8-10}$ and do not consider themselves to have a mental illness. ${ }^{11}$ In an attempt to address this, the routine screening of patients with diabetes and coronary heart disease for concurrent depression has been widely advocated ${ }^{12,13}$ and has now been introduced into the UK general practice contract. ${ }^{14}$

However, the arguments put forward for depression screening not only apply to patients with diabetes or coronary heart disease but also extend to other groups that are at high risk. ${ }^{11}$ One such group are patients presenting with painful conditions. Depression occurs up to four times more frequently in those with persistent pain than in those without. ${ }^{15-18}$ The issues surrounding screening in this group are, arguably, not just confined to diagnosing depressive disorder but also in detecting concurrent depressive symptoms that may amplify the suffering caused by pain $^{19}$ and are consistently associated with a poorer prognosis. ${ }^{20}$ Once recognised, collaborative care of

CD Mallen, BMedSci, MMedSci, MPhil, DROCG, DFFP, MRCGP, Cert Med Ed, lecturer in general practice, Arthritis Research Campaign National Primary Care Centre;

G Peat, BSc, MSc, PhD, MCSP, senior lecturer in clinical epidemiology, Primary Care Musculoskeletal Research Centre, Keele University, Keele, Staffordshire.

Address for correspondence

Dr Christian D Mallen, Arthritis Research Campaign National Primary Care Centre, Keele University, Keele, ST5 5BG. E-mail: c.d.mallen@cphc.keele.ac.uk

Submitted: 11 February 2008; Editor's response: 7 April 2008; final acceptance: 3 June 2008.

OBritish Journal of General Practice 2008; 58: 688-693.

DOI: 10.3399/bjgp08X342228 
comorbid depressive symptoms can, for example, help reduce arthritis pain and disability. ${ }^{21,22}$

Adequate performance of screening questions is a prerequisite for any recommendation on screening ${ }^{23}$ and, although there is some evidence that this criterion has been met, ${ }^{24}$ screening questions cannot be assumed to perform as well in older patients with pain. The presence of pain reduces the recognition of depression in routine practice, a problem that may be further exacerbated by multimorbidity in older age. ${ }^{18}$

In this study the ability of recommended depression case-finding questions, ${ }^{25}$ administered by the GP during the consultation, was investigated to detect depressive symptoms in older people presenting with musculoskeletal pain.

\section{METHOD}

\section{Design and setting}

This study was conducted as part of the PROG-RES study, a prospective cohort of older adults with musculoskeletal pain in primary care. Full details of this study have been described previously. ${ }^{26}$ Consecutive patients aged $\geq 50$ years presenting to five general practices in central Cheshire (44 GPs in total) with non-inflammatory musculoskeletal pain were eligible to participate in this study. Each practice recruited patients for between 3 and 4 months between September 2006 and March 2007. Patients were not eligible to participate if they had evidence of 'red flags' (significant traumatic injury; a red, hot, swollen joint), inflammatory arthropathy, or were deemed vulnerable by their GP (significant cognitive impairment, or terminal illness).

\section{Data collection}

Information on depression status, pain intensity, pain interference, episode duration, and widespread pain was collected by participating GPs during the consultation and recorded on a specially designed electronic template. Members of the Keele General Practice Research Partnership performed weekly downloads to identify patients who had activated the electronic template by searching for a study tag on their records. These patients were sent a postal questionnaire within 1 week of consultation and were asked to provide written informed consent to both medical record review and further contact.

\section{Outcome measures}

GPs screened all participants in the consultation for the presence of depression using two depression screening questions:

- During the last month have you often been bothered by feeling down, depressed, or hopeless?

\section{How this fits in}

Older people with musculoskeletal pain frequently experience comorbid

depressive symptoms. The currently recommended ultra-short depression

screening questions fail to identify a large number of those with depressive

symptoms, including six out of eight patients with severe symptoms.

- During the last month have you often been bothered by little interest or pleasure in doing things ${ }^{25}$

These questions are currently used by GPs in the UK to screen patients with coronary heart disease and diabetes as part of the Quality and Outcomes Framework (QOF) of the UK GP contract. ${ }^{14}$ Ultrashort depression screening tools have been demonstrated to work best at ruling out the presence of a depressive disorder, ${ }^{24}$ and, therefore, participants also completed the 14-item Hospital Anxiety and Depression Scale (HADS), ${ }^{27}$ which was included as part of the baseline self-completion postal questionnaire.

Although the HADS is not the gold standard for diagnosing depressive disorder in primary care, it is widely used to assess the severity of depressive symptoms and is recommended by the UK GP contract for use in general practice. When the HADS is compared with the gold-standard diagnostic instrument (the structured diagnostic interview), it performs well with a sensitivity of $90 \%$ and a specificity of $86 \% .{ }^{14}$ In this study the HADS was used as the reference standard, using the recommended NHS cut-offs to classify participants into one of four groups:

- No depressive symptoms (HADS 0-7);

- Mild depressive symptoms (HADS 8-10);

- Moderate depressive symptoms (HADS 11-14); and

- Severe depressive symptoms (HADS 15-21).

The two brief screening questions were also included as part of the self-completion questionnaire to compare their performance when asked verbally by a GP, with their performance when completed by the patient after the consultation. A 'yes' answer to either question was taken to indicate a positive screening result. ${ }^{28}$

\section{Statistical analysis}

Results of screening were cross-tabulated with HADS results using SPSS. Pre- and post-test probabilities were calculated. 
Table 1. GP-administered and self-administered screening results and participants' HADS depression score $(n=428)$.

\begin{tabular}{|c|c|c|c|c|c|c|}
\hline & \multicolumn{4}{|c|}{ HADS score ${ }^{a}$} & \multirow[b]{2}{*}{$\begin{array}{l}\text { Missing } \\
(n=5)\end{array}$} & \multirow[b]{2}{*}{$\begin{array}{c}\text { Total } \\
(n=428)\end{array}$} \\
\hline & $\begin{array}{l}\text { Severe } \\
(15-21) \\
(n=8)\end{array}$ & $\begin{array}{c}\text { Moderate } \\
(11-14) \\
(n=49)\end{array}$ & $\begin{array}{c}\text { Mild } \\
(8-10) \\
(n=93)\end{array}$ & $\begin{array}{c}\text { None } \\
(0-7) \\
(n=273)\end{array}$ & & \\
\hline \multicolumn{7}{|l|}{ GP-administered } \\
\hline Positive ${ }^{b}$ & 2 & 19 & 24 & 33 & 0 & 78 \\
\hline Negative $^{c}$ & 5 & 27 & 60 & 201 & 4 & 297 \\
\hline Unclassifiable & 1 & 3 & 9 & 39 & 1 & 53 \\
\hline \multicolumn{7}{|l|}{ Self-administered } \\
\hline Positive $^{b}$ & 8 & 45 & 69 & 93 & 3 & 218 \\
\hline Negative $^{c}$ & 0 & 4 & 23 & 178 & 1 & 206 \\
\hline Unclassifiable $^{d}$ & 0 & 0 & 1 & 2 & 1 & 4 \\
\hline
\end{tabular}

aHADS score categorised as per QOF; ' Answered 'yes' to at least one of the screening questions; 'Answered 'no' to both screening questions; 'Missing on both or negative on one and missing on the other. HADS = Hospital Anxiety and Depression Scale. QOF = Quality and Outcomes Framework.

\section{RESULTS}

GPs completed electronic templates on 650 patients, of which 502 responded to the baseline questionnaire (crude response $=77.2 \%$ ). Of these, $428(85.3 \%)$ baseline responders gave permission to have their medical records examined. In total, $60.0 \%$ of the study population were female; the mean age of participants was 63.1 years (standard deviation [SD] = 10.6). Mean HADS scores were similar for both baseline responders (6.1) and those giving permission for medical record review (6.2).

A total of $78(18.2 \%)$ participants screened positive for depression when assessed by their GP, 297 (69.4\%) participants screened negative, and it was not possible to classify $53(12.4 \%)$ participants due to incomplete or missing data (that is, both screening questions missed or one 'no' and one missed) (Table 1).

From the self-completion postal questionnaire $(n=$ 428), severe depressive symptoms were reported by eight participants $(1.9 \%)$, moderate depressive symptoms by 49 participants $(11.4 \%)$, mild depressive symptoms by $93(21.7 \%)$, and no depressive symptoms by 273 participants $(63.8 \%)$ (Table 1).

The pre- and post-test probabilities of having depressive symptoms are given in Table 2. The pretest probability of any depressive symptoms was $35.5 \%$ with a post-test probability of $57.7 \%$ in those screening positive after being screened by the GP.

Using data obtained from the questionnaire it was possible to compare the results of the two-item depression screening when administered by the GP with the results obtained when the same two-item depression screening items were self-administered at home (Table 1). A total of 218 (51.4\%) participants were classified as having depressive symptoms (positive) according to self-administered screening at home, compared with only 78 (20.8\%) on GPadministered screening in the consultation. There was little difference between GP-administered and selfadministered screening in the probability of depressive symptoms among those who screened positive. However, the probability of depressive symptoms among those who screened negative was much lower for self-administered screening (13.2\%) than for GP-administered screening (31.4\%) (Table 2).

\section{DISCUSSION}

\section{Summary of main findings}

Older patients consulting their GP with musculoskeletal pain frequently have comorbid mental ill health. It was found that $35.5 \%$ of study participants had evidence of depressive symptoms, with $13.5 \%$ suffering with moderate or severe symptoms. When GPs administered the screening questions in the consultation for musculoskeletal pain a large number of patients with depressive symptoms were missed. These included six out of eight patients classified as having severe depression.

Table 2. Pre- and post-test probabilities of depression by result of GP-administered and self-administered depression screening.

\begin{tabular}{|c|c|c|c|c|c|}
\hline & \multirow[b]{2}{*}{$\begin{array}{c}\text { Pre-test } \\
\text { probability (\%) }\end{array}$} & \multicolumn{2}{|c|}{$\begin{array}{c}\text { GP-administered } \\
\text { depression screening }\end{array}$} & \multicolumn{2}{|c|}{$\begin{array}{c}\text { Self-administered } \\
\text { depression screening }\end{array}$} \\
\hline & & $\begin{array}{l}\text { Post-test probability if } \\
\text { screened positive (\%) }\end{array}$ & $\begin{array}{l}\text { Post-test probability if } \\
\text { screened negative (\%) }\end{array}$ & $\begin{array}{l}\text { Post-test probability if } \\
\text { screened positive (\%) }\end{array}$ & $\begin{array}{l}\text { Post-test probability } \\
\text { if screened negative (\%) }\end{array}$ \\
\hline Severe depression & $\begin{array}{c}8 / 423 \\
(1.9) \\
\end{array}$ & $\begin{array}{l}2 / 78 \\
(2.6)\end{array}$ & $\begin{array}{c}5 / 293 \\
(1.7) \\
\end{array}$ & $\begin{array}{c}8 / 215 \\
(3.7) \\
\end{array}$ & $\begin{array}{c}0 / 205 \\
(0)\end{array}$ \\
\hline $\begin{array}{l}\text { Moderate/severe } \\
\text { depression }\end{array}$ & $\begin{array}{c}57 / 423 \\
(13.5) \\
\end{array}$ & $\begin{array}{l}21 / 78 \\
(26.9)\end{array}$ & $\begin{array}{c}32 / 293 \\
(10.9)\end{array}$ & $\begin{array}{c}53 / 215 \\
(24.7) \\
\end{array}$ & $\begin{array}{c}4 / 205 \\
(2.0) \\
\end{array}$ \\
\hline $\begin{array}{l}\text { Mild/moderate/severe } \\
\text { depression }\end{array}$ & $\begin{array}{c}150 / 423 \\
(35.5)\end{array}$ & $\begin{array}{l}45 / 78 \\
(57.7)\end{array}$ & $\begin{array}{c}92 / 293 \\
(31.4) \\
\end{array}$ & $\begin{array}{c}122 / 215 \\
(56.7)\end{array}$ & $\begin{array}{c}27 / 205 \\
(13.2) \\
\end{array}$ \\
\hline No depression & $\begin{array}{c}273 / 423 \\
(64.5)\end{array}$ & $\begin{array}{l}33 / 78 \\
(42.3)\end{array}$ & $\begin{array}{c}201 / 293 \\
(68.6)\end{array}$ & $\begin{array}{c}93 / 215 \\
(43.3)\end{array}$ & $\begin{array}{c}178 / 205 \\
(86.8)\end{array}$ \\
\hline
\end{tabular}

Numbers not equal to 428 as per Table 1 because of missing data. 


\section{Strengths and limitations of the study}

There are some limitations to this study that need to be considered. It was not possible to classify 53 participants because of missing or incomplete GP screening data. There was a higher level of missing data for the second depression screening question than the first (12.6\% versus $7.5 \%$ ) and data were more likely to be missing from this question if the response to the first screening question was 'yes' (16.4\% versus $6.5 \%)$. This would suggest that GPs were more likely to skip the second question if the answer to the first was 'yes' and this would imply that GPs are already using one 'yes' response to indicate a positive screen. If it were to be assumed that all of the unclassifiables would screen negative, the posttest probability changed only slightly (data not shown). One 'yes' response was chosen to the screening questions to indicate a positive result, an approach that has been recommended by others. ${ }^{11,28}$ Using two 'yes' responses did not confer any major improvement (data not shown).

A further potential limitation could be the time delay between the administration of the screening questions in the consultation and the participant completing the postal questionnaire. Participants received questionnaires within 1 week of their consultation and the mean time to response (receipt of a completed questionnaire) was 16 days. However, when the analysis was restricted to people who returned their questionnaire within 7 days of their GP consultation, the same results were found (data not shown), giving confidence that time delay did not significantly affect the results.

\section{Comparison with existing literature}

Two-item depression screening has been validated for both verbal ${ }^{28}$ and written ${ }^{29}$ use, and the performance of both methods has previously been reported to be broadly similar. ${ }^{24}$ The head-to-head comparison between GP-administered (verbal) and self-administered (written) screening in this study does not support previously published findings. When the GP used verbal screening just $20.8 \%$ screened positive for depression, compared with $51.4 \%$ screening positive when the self-administered written form was used.

Without direct observation of how the questions are asked in the consultation, it is difficult to provide firm conclusions on why this might be. Health professionals, predominately GPs and practice nurses, have been using these screening questions for over a year as part of their routine clinical practice and may have adapted them to allow their use to be better integrated into the consultation. GPs may be using screening questions in the consultation in a way that limits the prevalence of those who may screen positive but without reducing the probability of finding cases of depression (hence post-test probabilities almost identical). In part, this may reflect the patient's agenda: some choose to prioritise their pain, rather than their psychological health, yet feel able to admit low mood when at home. This may be 'rational selection' but the result is that many more cases are missed in the consultation than would be found by self-administered screening (hence the difference in post-test probabilities of those who screened negative).

The high levels of comorbid depressive symptoms found in the current study using the HADS are comparable to the levels demonstrated in other chronic illnesses such as coronary heart disease ${ }^{30,31}$ and diabetes. ${ }^{32,33}$ To date, less is known about the prevalence of comorbid depressive symptoms in older patients with musculoskeletal pain, ${ }^{17}$ although the high prevalence of depressive symptoms in patients with fibromyalgia (estimates range from $20-80 \%)^{34,35}$ and low back pain $(20 \%)^{36}$ suggest that chronic pain syndromes and depressive symptoms frequently coexist.

A recent, large, multinational, population-based study $^{37}$ found that $10.7 \%$ (95\% confidence interval = 9.1 to 12.3) of those with arthritis also had depressive disorder (diagnosed using the World Mental Health survey version of the Composite International Diagnostic Interview), and a primary-care-based study estimated that around $19 \%$ of patients with osteoarthritis had moderate depressive symptoms, as assessed by the PHQ-9.17 Both the PHQ-9 and HADS are widely used in primary care to assess the severity of depressive symptoms and, although they both demonstrate acceptable reliability, convergent/ discriminant validity, and responsiveness to change, they differ considerably in how they categorise severity. ${ }^{38}$

\section{Implications for future research and clinical practice}

The recent publication of the NICE osteoarthritis guidelines ${ }^{39}$ recommends screening for depression in people over the age of 45 years with joint pain and functional limitation, as part of a holistic assessment in general practice. However, no recommendation is made as to how this should happen in practice. Ultrashort depression screening questions do not appear to work for older people with musculoskeletal pain, although they are widely used to screen patients with diabetes and coronary heart disease since inclusion in the GP contract. ${ }^{14}$ The long-term impact of this has yet to be evaluated fully.

The routine screening for depression in generalpractice settings remains controversial, despite the positive recommendations made by both $\mathrm{NICE}^{11}$ and the US Preventive Services Task Force. ${ }^{40}$ Screening 
alone cannot improve the outcome of depression ${ }^{41,42}$ but, given the possible health gains of effective intervention for comorbid depression in adults with arthritis, it is reasonable to ask whether screening questions actually help identify potential cases. From this cross-sectional analysis it is not possible to know the outcome of those patients 'missed' by the screening tool. Kessler et $\mathrm{a}^{/ 33}$ found that although many patients with depression did not receive a diagnosis at an initial consultation, most went on to have their depression diagnosed at later encounters. Furthermore, research has demonstrated that missed cases of depression may not have a poorer prognosis ${ }^{44}$ and that those who are missed tend to have less severe symptoms. ${ }^{45}$

Although the findings confirm that older people with musculoskeletal pain do represent a group at high risk of depression, the relatively poor performance of GPadministered screening suggests that routine depression screening by GPs in this patient group cannot be recommended currently. The high consultation prevalence of musculoskeletal conditions (approximately 60 per 1000 adults aged $\geq 50$ years in the registered practice population per year $)^{46}$ is an additional concern that may restrict the feasibility of routine screening, particularly given the potentially large numbers of patients who could be screened as positive but were found to have either no or only mild (and perhaps remitting) depressive symptoms. An improvement in the performance of screening questions in this patient group, for example, asking those who are falsely screened as positive the additional question: 'is this something with which you would like help?'47 or narrowing the definition of 'high risk' from all patients aged $\leq 50$ years presenting with musculoskeletal pain could help in this regard.

\section{Funding body}

Christian Mallen is funded by an Arthritis Research Campaign Primary Care Fellowship (MO669)

\section{Ethical approval}

Ethical approval was obtained from the Central Cheshire Local Research Ethics Committee (06/Q1503/60)

\section{Competing interests}

The authors have stated that there are none

\section{Acknowledgements}

We would like to thank the administration and research network team at the Primary Care Musculoskeletal Research Centre. We would also like to thank Professor Peter Croft, Dr Elaine Thomas, Ms Charlotte Clements, and all the Central Cheshire general practices and patients who participated in this study.

\section{Discuss this article}

Contribute and read comments about this article on the Discussion Forum: http://www.rcgp.org.uk/bjgp-discuss

\section{REFERENCES}

1. McCormick A, Fleming D, Charlton J. Morbidity statistics from general practice: fourth national study 1991-1992. London: HMSO, 1995.

2. Singleton N, Bumpstead R, O'Brien M, et al. Psychiatric morbidity among adults living in private households, 2000: summary report. London: Office for National Statistics, 2000. www.statistics.gov.uk/downloads/theme_health/psychmorb_sumrep.p df (accessed 10 Jun 2008)

3. Licht-Strunk E, van der Kooij KG, van Schaik DJ, et al. Prevalence of depression in older patients consulting their general practitioner in the Netherlands. Int J Geriatr Psychiatry 2005; 20(1): 1013-1019.

4. Davidson JR, Meltzer-Brody SE. The underrecognition and undertreatment of depression: what is the breadth and depth of the problem? J Clin Psychiatry 1999; 60(Suppl 7): 4-9.

5. Kessler D, Lloyd K, Lewis G, Gray DP. Cross-sectional study of symptom attribution and recognition of depression and anxiety in primary care. BMJ 1999; 318(7181): 436-439.

6. Klinkman M. The role of algorithms in the detection and treatment of depression in primary care. J Clin Psychiatry 2003; 64(Suppl 2): 19-23.

7. Falagas ME, Vardakas KZ, Vergidis PI. Under-diagnosis of common chronic diseases: prevalence and impact on human health. Int J Clin Pract 2007; 61(9): 1569-1579.

8. Dowrick C, Katona C, Peveler R, Lloyd H. Somatic symptoms and depression: diagnostic confusion an clinical neglect. Br J Gen Pract 2005; 55(520): 829-830.

9. Drayer RA, Mulsant BH, Lenze EJ, et al. Somatic symptoms of depression in elderly patients with medical comorbidities. Int $J$ Geriatr Psychiatry 2005; 20(10): 973-982.

10. Tylee A, Gandhi P. The importance of somatic symptoms in depression in primary care. Prim Care Companion J Clin Psychiatry 2005; 7(4): 167-176.

11. NICE. Depression: management of depression in primary and secondary care. National Clinical Practice Guideline Number 23. London: NICE, 2007.

12. Davies SJ, Jackson PR, Potokar J, Nutt DJ. Treatment of anxiety and depressive disorders in patients with cardiovascular disease. BMJ 2004; 328(7445): 939-943

13. Goldney RD, Phillips PJ, Fisher LJ, Wilson DH. Diabetes, depression, and quality of life: a population study. Diabetes Care 2004; 27(5): $1066-1070$.

14. NHS Employers. Revisions to the GMS contract 2006/07. Annexe 1: Quality and Outcomes Framework guidance 2006/2007. London: NHS, 2006

15. Gureje O, Von Korff M, Simon GE, Gater R. Persistent pain and wellbeing: a World Health Organization study in primary care. JAMA 1998; 280(2): 147-151.

16. Arnow BA, Hunkeler EM, Blasey CM, et al. Comorbid depression, chronic pain, and disability in primary care. Psychosom Med 2006; 68(2): 262-268.

17. Rosemann T, Backenstrass M, Joest $K$, et al. Predictors of depression in a sample of 1021 primary care patients with osteoarthritis. Arthritis Rheum 2007; 57(3): 415-422.

18. Bair MJ, Robinson RL, Katon W, Kroenke K. Depression and pain comorbidity: a literature review. Arch Intern Med 2003; 163(20): 2433-2445.

19. Katona C, Peveler R, Dowrick C, et al. Pain symptoms in depression definition and clinical significance. Clin Med 2005; 5(4): 390-395.

20. Mallen CD, Peat G, Thomas E, et al. Prognostic factors for musculoskeletal pain in primary care: a systematic review. $\mathrm{Br} J \mathrm{Gen}$ Pract 2007; 57(541): 655-661.

21. Lin EH, Katon W, von Korff M, et al. Effect of improving depression care on pain and functional outcomes among older adults with arthritis: a randomised controlled trial. JAMA 2003; 290(18): $2428-2429$.

22. Lin E, Tang L, Katon W, et al. Arthritis pain and disability: response to collaborative depression care. Gen Hosp Psychiatry 2006, 28(6): $482-486$.

23. National Screening Committee. First Report of the National Screening Committee. Health Departments of the United Kingdom. NSC: London, 1998

24. Mitchell AJ, Coyne JC. Do ultra-short screening instruments accurately detect depression in primary care? A pooled analysis and meta-analysis of 22 studies. Br J Gen Pract 2007; 57(535): 144-151.

25. Kroenke K, Spitzer RL, Williams JB. The Patient Health Questionnaire2: validity of a two-item depression screener. Med Care 2003; 41(11): 1284-1292.

26. Mallen CD, Peat G, Thomas E, et al. The assessment of the prognosis of musculoskeletal conditions in older adults presenting to general practice: a research protocol. BMC Musculoskelet Disord 2006; 7: 84

27. Zigmond AS, Snaith RP. The hospital anxiety and depression scale. Acta Psychiatr Scand 1983; 67(6): 361-370. 
28. Arroll B, Khin N, Kerse N. Screening for depression in primary care with two verbally asked questions: cross-sectional study. BMJ 2003; 327(7424): 1144-1146.

29. Whooley MA, Avins AL, Miranda J, Browner WS. Case-finding instruments for depression. Two questions are as good as many. J Gen Intern Med 1997; 12(7): 439-445.

30. Spertus JA, McDonell M, Woodman CL, Fihn SD. Association between depression and worse disease-specific functional status in outpatients with coronary artery disease. Am Heart J 2000; 140(1): 105-110.

31. Ruo B, Rumsfeld JS, Hlatky MA, et al. Depressive symptoms and health-related quality of life: the Heart and Soul study. JAMA 2003; 290(2): 215-221.

32. Anderson RJ, Freedland KE, Clouse RE, Lustman PJ. The prevalence of comorbid depression in adults with diabetes: a meta-analysis. Diabetes Care 2001; 24(6): 1069-1078.

33. Ali S, Stone MA, Peters JL, et al. The prevalence of co-morbid depression in adults with type 2 diabetes: a systematic review and meta-analysis. Diabet Med 2006; 23(11): 1165-1173.

34. Fietta P, Fietta P, Manganelli P. Fibromyalgia and psychiatric disorders. Acta Biomed 2007; 78(2): 88-95.

35. Kassam A, Patten SB. Major depression, fibromyalgia and labour force participation: a population-based cross-sectional study. $B M C$ Musculoskelet Disord 2006; 7: 4.

36. Currie SR, Wang J. Chronic back pain and major depression in the general Canadian population. Pain 2004; 107(1-2): 54-60.

37. Moussavi S, Chatterii S, Verdes E, et al. Depression, chronic diseases, and decrements in health: results from the World Health Surveys. Lancet 2007; 370(9590): 851-858

38. Cameron IM, Crawford JR, Lawton K, Reid IC. Psychometric comparison of PHQ-9 and HADS for measuring depression severity in primary care. Br J Gen Pract 2008; 58(546): 32-36.

39. The National Collaborating Centre for Chronic Conditions. Osteoarthritis: national clinical guideline for care and management in adults. London: Royal College of Physicians, 2008.

http://www.nice.org.uk/nicemedia/pdf/CG059FullGuideline.pdf (accessed 10 Jun 2008).

40. Pignone MP, Gaynes BN, Rushton JL, et al. Screening for depression in adults: a summary of the evience for the US Preventive Services Task Force. Ann Intern Med 2002; 136(10): 765-776.

41. Palmer SC, Coyne JC. Screening for depression in medical care: pitfalls, alternatives, and revised priorities. J Psychosom Res 2003; 54(4): 279-287.

42. Gilbody S, Sheldon T, Wessely S. Should we screen for depression? BM 2006; 332(7548): 1027-1030

43. Kessler D, Bennewith O, Lewis G, Sharp D. Detection of depression and anxiety in primary care: follow up study. BMJ 2002; 325(7371): 1016-1017.

44. Dowrick C, Buchan I. Twelve month outcome of depression in general practice: does detection or disclosure make a difference? BMJ 1995: 311(7015): 1274-1276.

45. Goldberg D, Privett M, Ustun B, et al. The effects of detection and treatment on the outcome of major depression in primary care: a naturalistic study in 15 cities. Br J Gen Pract 1998; 48(437): 1840-1844.

46. Jordan K, Clarke AM, Symmons DP, et al. Measuring disease prevalence: a comparison of musculoskeletal disease using four general practice consultation databases. Br J Gen Pract 2007; 57(534): 7-14.

47. Arroll B, Goodyear-Smith F, Kerse N, et al. Effect of the addition of a 'help' question to two screening questions on specificity for diagnosis of depression in general practice: diagnostic validation study. BMJ 2005; 331(7521): 884 